\title{
O desenvolvimento rural sob regime de verdade: o discurso do Banco Mundial*
}

\author{
Mariana Bombo Perozzi Gameiro \\ \& Rodrigo Constante Martins**
}

Resumo: O objetivo deste trabalho é interpretar sociologicamente os discursos do Banco Mundial no campo das lutas cognitivas pela construção do saber e das prescrições legítimas para o desenvolvimento rural. Tais discursos foram buscados em cinco relatórios do banco dedicados ao tema entre 1995 e 2015, os quais evidenciam um deslocamento do lugar da agricultura para o rural. No período em análise, os documentos iniciais visam construir uma visão alargada dos espaços rurais, numa abordagem territorializada que estimula a diversificação econômica e a participação coletiva. Num segundo momento, a ênfase desloca-se em direção ao fortalecimento da agricultura e à necessidade de elevação da produtividade agrícola para garantia da segurança alimentar da população mundial; essa posição é reforçada num terceiro momento, quando o banco associa a agricultura às mudanças climáticas. O estudo destaca que as prescrições sobre o desenvolvimento rural empreendidas pela instituição estão calcadas nos recursos universais de cálculo e previsibilidade próprios da ciência moderna. Disso decorre a avaliação e a modelagem das trocas materiais e simbólicas tomadas como legítimas nos territórios rurais - ações que incorrem sobre as práticas da população rural e demandam a docilização dos corpos para novos controles institucionais e de mercado na relação com o meio ambiente. A eficácia da reforma do discurso do banco sobre desenvolvimento rural em países emergentes também se articula com a fluidez dos espaços de dominação e exercício do poder em escala global.

Palavras-chave: desenvolvimento rural, novas ruralidades, ruralidades e teoria social, Banco Mundial.

\section{Introdução}

ste artigo discute os termos dos principais relatórios sobre desenvolvimento rural e agricultura produzidos pelo Banco Mundial nas últimas duas décadas. O estudo sustenta que o banco concorre na disputa cognitiva para a definição das categorias legítimas de classificação do desenvolvimento rural em escala internacional, com atenção aos contextos de investimentos nos países em desenvolvimento. Para tanto, capitaliza suas intervenções no debate público acionando recursivamente a autoridade concernente ao discurso científico.

Ao afirmar que o Banco Mundial se ancora não apenas em seu poder financeiro, mas também no conhecimento especializado alavancado por seu corpo técnico, este artigo remete ao conceito de sistemas peritos, que Giddens (1991) define como sendo os sistemas de excelência técnica ou competência profissional que organizam gran-
Recebido: 20.11 .16

Aprovado: 20.09.17 
des áreas dos ambientes material e social que vivemos. Os sistemas peritos proporcionam o desencaixe das relações sociais, ou seja, o deslocamento das relações sociais de contextos locais de interação, com sua reestruturação através de extensões indefinidas de tempo e espaço. A multiplicidade de opiniões científicas implícitas à maioria dos temas que circundam nossas atividades cotidianas faz com que os sistemas peritos representem, também, uma fonte de insegurança para os indivíduos (Giddens, 2002) -, motivo pelo qual a construção de consensos em torno de temas politicamente estratégicos, via redes de especialistas, faz-se altamente desejável.

Neste trabalho, a relevância da posição do saber perito no deslocamento espaço-temporal das relações sociais será tomada apenas como ponto de partida. O discurso sobre desenvolvimento rural produzido por grupos de especialistas do Banco Mundial será compreendido nos termos desse deslocamento legitimado pelo fenômeno da confiança. Entretanto, sua complexidade demanda um arranjo conceitual capaz de supor a hierarquização dos espaços e dos saberes implicados neste processo. Por isso, neste estudo, também lançaremos mão do conceito de espaço de fluxos formulado por Castells (1996), bem como das análises de Foucault acerca da construção de regimes de verdade, para interpretar o discurso do Banco Mundial no campo das lutas cognitivas pela construção do saber e das prescrições legítimas para o desenvolvimento rural. Para tanto, deve-se compreender o rural como categoria de pensamento relacional do mundo social, que define identidades, sustenta reivindicações e encontra sentido operacional na utilização que os atores sociais fazem para classificar o mundo e a si próprios (Carneiro, 2008).

1. Os relatórios analisados neste artigo indicam copyright para The International Bank for Reconstruction and Development; The World Bank e, do mesmo modo que em tais documentos, aqui serão referidos como Banco Mundial, banco ou apenas a instituição.

2. The World Bank $>$ Publications > Documents and Reports $>$ Browse by Topic $>$ Rural Development $>$ All Rural Development. Consulta realizada em: 29 Abr. 2015 (World Bank, 2015).
O artigo adota a análise documental como procedimento metodológico, tendo detectado que as principais propostas elaboradas pelo Banco Mundial ${ }^{1}$ para o desenvolvimento rural e a agricultura nas duas últimas décadas encontram-se reunidas em cinco documentos oficiais. Relacionados no Quadro 1, estes documentos foram lançados em intervalos não regulares e, conforme veremos, quando relacionados entre si, revelam diferenças na abordagem da relação entre agricultura e desenvolvimento rural.

A pesquisa pelo tópico "rural development" na seção de publicações da página eletrônica do Banco Mundial, efetuada pela primeira vez em 2011 e pela última em 2015, resultou na listagem de 13.102 documentos (análises gerais, projetos para implementação de financiamentos, relatórios de avaliação de investimentos, working papers, declarações oficiais e outros, com enfoque global ou por país/Estado/ região) assinados pela instituição entre 1947 e 2015, em diversas línguas² (World Bank, 2015). Para a seleção dos cinco documentos que compõem esta pesquisa, foram estabelecidos os seguintes critérios: 
a. delimitação temporal (1995 a 2015, sendo as principais publicações identificadas entre 1997 e 2013);

b. delimitação geográfica (apenas documentos de abrangência global);

c. caráter essencialmente estratégico para o banco, perceptível a partir de informações declaradas pela própria instituição e, também, devido à recorrente referência a tais documentos em outros materiais do próprio banco. Assim, foram eleitos os seguintes documentos para análise:

QUADRO 1.

PRINCIPAIS DOCUMENTOS PUBLICADOS PELO BANCO MUNDIAL SOBRE O TEMA DESENVOLVIMENTO RURAL, NO PERÍODO DE 1995 A 2015

\begin{tabular}{|c|c|c|}
\hline Título & Publicação & Páginas \\
\hline Rural development: from vision to action & 1997 & 236 \\
\hline Reaching the rural poor - a renewed strategy for rural development & 2003 & 208 \\
\hline World development report 2008: agriculture for development & 2007 & 386 \\
\hline $\begin{array}{l}\text { Implementing agriculture for development - World Bank Group agriculture action plan: FY } \\
\text { 2010-2012 }\end{array}$ & 2009 & 72 \\
\hline $\begin{array}{l}\text { Implementing agriculture for development - World Bank Group agriculture action plan: FY } \\
\text { 2013-2015 }\end{array}$ & 2013 & 132 \\
\hline
\end{tabular}

Fonte: Elaboração dos autores, com base em pesquisa documental.

Para a tarefa de interpretação destes documentos, tendo em vista a identificação de uma possível nova gramática em torno do tema desenvolvimento rural, somamos às referências analíticas já mencionadas as contribuições foucaultianas acerca da ordem do discurso. Foucault (2009) parte da hipótese que, em toda sociedade, a produção do discurso é, ao mesmo tempo, controlada, selecionada, organizada e redistribuída por certo número de procedimentos que têm por função conjurar seus poderes e perigos, dominar seu acontecimento aleatório, esquivar sua materialidade. Por pertencer à elite dominante que circula nos espaços de fluxos, o Banco Mundial manipula essas regras a seu favor. Entre os procedimentos de controle do discurso que Ihes são externos, destacamos o que Foucault (2009) chamou de vontade de verdade, que representa a pressão e o poder de coerção de um discurso, apoiado no suporte e na distribuição institucional sobre outros discursos.

Veremos, então, que os discursos do Banco Mundial sobre os espaços rurais, seus modelos de desenvolvimento e as funções da agricultura ajustam-se aos interesses internos da instituição e carregam uma vontade de verdade, estando institucionalmente apoiados por estudos, livros e relatórios que pretendem se fazer legítimos e unívocos, lançando como estratégia o apelo à cientificidade. 
O problema que levantamos neste artigo é que as categorias de interpretação de mundo fomentadas pelo banco não interferem apenas simbolicamente na construção de sentidos para o rural. Associadas à capacidade de investimentos da instituição, elas apresentam efeitos concretos, que acabam por desterritorializar o rural do espaço de lugares, aquele da experiência cotidiana. Consequentemente, lança-o para o espaço de fluxos, onde a assimetria das relações de poder favorece indivíduos e organizações cujas lógicas seguem as racionalidades ali predominantes. Retira-se, assim, os agentes enraizados no lugar da potencialidade de nomeação de interesses acerca de tais espaços, independentemente da retórica adotada pelo banco.

O artigo encontra-se, então, divido em seis seções. Após esta introdução, o segundo tópico traçará um breve histórico da atuação do Banco Mundial no tocante ao desenvolvimento rural, abrindo caminho para a análise documental que se procederá nas seções seguintes. Na terceira seção será discutido o indicativo do banco, em relatório de 1997, sobre a necessidade de se pensar o desenvolvimento rural em termos de investimentos e geração de renda também a partir de atividades não agrícolas. Na quarta é apresentada a retomada da visão estratégica da instituição sobre a agricultura, definindo suas prescrições para os países em desenvolvimento. Na quinta seção é discutido o modo como o banco reposiciona sua visão sobre o desenvolvimento rural através do reconhecimento das possibilidades de investimentos e obtenção de lucros sobre recursos ecossistêmicos. Por fim, nas considerações finais, são sumarizadas as principais conclusões do estudo.

\section{Propostas do}

\section{Banco Mundial para os espaços rurais}

Desde sua criação, em 1944, o Banco Mundial explorou a sinergia entre dinheiro, prescrições políticas e conhecimento econômico para ampliar sua influência e institucionalizar sua pauta de intervenção, tanto por meio da coerção como da persuasão (Pereira, 2010). A instituição se define como "uma fonte vital de assistência financeira e técnica para países em desenvolvimento" (World Bank, 2014), atuando na concessão de empréstimos e outras subvenções nas áreas de educação, saúde, administração pública, infraestrutura, agricultura, meio ambiente e gestão de recursos naturais, bem como para o desenvolvimento do setor privado e financeiro. Alguns de seus projetos são cofinanciados por governos, instituições multilaterais, bancos comerciais, agências de crédito e investidores privados.

O Banco Mundial é composto pelo Banco Internacional para Reconstrução e Desenvolvimento (Bird) e pela Associação Internacional de Desenvolvimento (AID). 
Em conjunto com outras três corporações internacionais financeiras, eles formam o Grupo Banco Mundial². Em 2014, o Bird contava com 188 países membros, representados por um quadro de governadores, geralmente ministros da fazenda ou do desenvolvimento, ou presidentes do Banco Central dos países membros (World Bank, 2014). O poder de voto dentro do Bird é proporcional à contribuição financeira do país à instituição 4 .

As primeiras décadas de existência do Banco Mundial foram marcadas pela preocupação da instituição em conquistar uma posição de respeito no mercado financeiro, o que causou relativo atraso ao envolvimento da instituição com a temática do desenvolvimento rural. Além disso, vários dos principais nomes da economia do desenvolvimento da época concebiam a indústria como o motor do crescimento, de modo que a importância da agricultura para o desenvolvimento econômico geral não era reconhecida pelo banco, que destinava irrelevantes recursos para este segmento (Castro, 2004).

Na década de 1960, porém, a instituição começou a dar atenção à agricultura, num movimento facilitado pela criação da Associação Internacional de Desenvolvimento (International Development Association - IDA), braço do Banco Mundial que possibilitou a expansão das atividades do banco para os países mais pobres (Hone, 1972). Com o crescimento da população mundial, a produção de alimentos tornava-se insuficiente e o investimento em pequenos agricultores começou a ser avaliado pelo banco como estratégia para contornar o problema da fome e manter o abastecimento dos países do Norte, importadores de alimentos. No final da década de 1960, países da América Latina, África e Ásia eram palco de ocupações, reformas na legislação agrária e lutas por descolonização, despertando o temor de que conflitos sociais e políticos se intensificassem, sobretudo em áreas de grandes desigualdades de acesso à terra (Gonzales et alii, 1990).

Na década de 1970, o Banco Mundial ajustou seu foco para as políticas sociais de "superação da pobreza", ante os investimentos então concentrados em infraestrutura. Neste contexto, a instituição apresentou seu Programa de Desenvolvimento Rural Integrado (PDRI), programa de crédito que tinha como objetivo a criação de mercado para produtos rurais, integrado a programas de extensão e educação básica, construção de estradas e sistemas de irrigação, estabelecimento de indústrias rurais, criação de obras públicas nos campos e desenvolvimento de centros de saúde e planejamento familiar. Essas variadas atividades deveriam ser sincronizadas numa área geográfica selecionada, tendo como pressuposto a aceitação da estrutura agrária. Era este o embrião das propostas que o banco formularia para o desenvolvimento rural cerca de 20 ou 30 anos depois (Gameiro, 2013).
3. As outras três corporações que formam, junto com o Bird e a AID, o Grupo Banco Mundial são, na nomenclatura original, o International Finance Corporation (IFC); a Multilateral Investment Guarantee Agency (Miga); e o International Centre for Settlement of Investment Disputes (Icsid).

4. Em junho de 2014 o poder de voto dos Estados Unidos equivalia a $15 \%$ do total; o Japão tinha 8\%, a China, 5\%, e França, Alemanha e Reino Unido, entre 4\% e 4,5\% cada; Rússia, Arábia Saudita, Canadá, Holanda, Espanha e Itália com cerca de $2 \%$ dos votos cada; e o Brasil com 1,7\% dos votos (World Bank, 2014). 
Os discursos do Banco Mundial circulam nos ritos sociais e, sobretudo, entre agentes e instituições, ora interferindo sobre e ora sendo recurso de ação no espaço social. No caso do debate sobre desenvolvimento rural - e em particular no contexto da alta modernidade (Giddens, 2002) -, é o próprio rural que passa a circular, como valor e espaço simbólico objeto de distintos interesses sociais (Mormont, 1996). Conforme buscaremos evidenciar no curso da análise, o discurso promovido pelo Banco Mundial sobre o espaço rural na passagem do século XX ao XXI termina por desterritorializar o rural, lançando-o do espaço de lugares (palco da experiência cotidiana em situações de copresença, onde vive a maioria dos indivíduos, enraizada em suas histórias, experiências e costumes) ao espaço de fluxos. Como bem discute Castells (1996) a propósito da sociedade informacional, este deslocamento tem implicações decisivas no plano das relações de poder, isso porque o espaço de fluxos é o suporte material de novos processos de dominação: os que dispõem de mais informação, em tese, dispõem de mais condições de exercer poder, não desconsiderando as possibilidades de resistência e questionamento à legitimidade de relações de dominação que não são apenas estruturais, mas também estabelecidas, concebidas e implementadas por atores sociais.

Segundo a teoria do espaço de fluxos, as sociedades são organizadas de maneira assimétrica em torno de interesses dominantes específicos a cada sistema social. O espaço de fluxos seria dominante por ser a lógica dos interesses de instituições cujas funções e procedimentos internos são estratégicos para a formulação e reprodução de práticas sociais, como é o caso do Banco Mundial. Passaremos, no próximo tópico, à análise dos documentos da instituição.

\section{O desenvolvimento rural \\ para além da agricultura}

Nas décadas de 1960 e 1970, como mencionamos há pouco, os investimentos do Banco Mundial direcionados aos espaços rurais aumentaram em função de interesses estratégicos internamente estabelecidos pela própria instituição. Porém, ao longo das décadas de 1980 e 1990, o comprometimento da organização - assim como o da comunidade internacional -, para com o desenvolvimento rural diminuiu, conforme constata o Banco Mundial no primeiro relatório analisado neste artigo, intitulado Rural development: from vision to action - a sector strategy paper, publicado pela organização em março de 1997. Segundo o banco, essa reduzida atenção ocorria num conjunto grande de países devido a uma visão da agricultura como setor declinante em termos de geração de empregos e renda, tendo em vista a queda dos preços dos alimentos nessas duas décadas. Ademais, o próprio poder político das chamadas elites urbanas enviesava políticas, instituições e padrões de 
gastos nos países em desenvolvimento. Na arena internacional também haveria a mesma complacência relacionada aos preços dos produtos agrícolas em baixa, além da frágil coordenação entre as organizações internacionais de comércio.

No âmbito do Banco Mundial, a atenção ao desenvolvimento rural teria diminuído porque o processo de formulação de estratégias no setor era fraco e os programas anteriores assistidos pelo banco na área registraram, em geral, mau desempenho. Dentre estes, estariam as experiências de desenvolvimento rural integrado, que consistiam em projetos top-down excessivamente centralizados; o suporte financeiro a culturas ou a setores específicos, como pecuária ou agroindústrias; o estímulo à abertura e ocupação de novas fronteiras agrícolas; a construção de sistemas de irrigação de grande escala; e o suporte ao envolvimento direto de instituições estatais no fornecimento de insumos, na produção, no processamento e na comercialização agrícola (World Bank, 1997).

Essa visão autocrítica do banco estava de acordo com uma produção acadêmico-científica gerada em diferentes áreas (sociologia rural, economia agrícola e outras) nos anos 1980-1990, a qual destaca as limitações dos modelos de desenvolvimento rural que marcaram os anos 1970-1980 nos países em desenvolvimento (Abramovay, 2000; Favareto, 2007; Lowe, 1999; Marsden \& Murdoch, 1998; Ploeg, 2000; Schneider, 2004; Veiga, 2000). Esta convergência inicial é função da necessidade de legitimação das proposições do banco e decorre mesmo do fato de os consultores da instituição serem, com frequência, atuantes também na academia. Os pontos de contato entre a produção discursiva do Banco Mundial e a científica se localizam, sobretudo, no diagnóstico dos problemas apresentados pelas políticas de desenvolvimento rurais até então empreendidas. A partir dos anos 1970, o modelo exógeno de desenvolvimento rural começou a cair em descrédito por promover um desenvolvimento dependente, baseado em subsídios continuados e decisões políticas tomadas por quadros técnicos ou políticos distantes. Além disso, este modelo promovia um desenvolvimento distorcido, que impulsionava determinados setores e tipos de negócios e negligenciava aspectos não econômicos da vida rural, apagando as diferenças culturais e ambientais.

Ao acompanhar as críticas, a literatura acadêmica gerava uma profusão de novos aportes para o desenvolvimento rural, quase sempre enfatizando a necessidade de deslocar o enfoque do agricultor para as redes de atores do setor agrícola para o espaço rural alargado, das ações do tipo top-down (de cima para baixo) para as bottom-up (de baixo para cima), com grande incentivo à participação das comunidades locais no desenho e na operacionalização das políticas e ações voltadas ao campo. As prescrições normativas de especialistas internos e externos ao banco tendiam, 
5. A literatura sociológica avançou na direção crítica quando avaliou os resultados de uma série de novas políticas de desenvolvimento rural territorializadas, descentralizadas

e participativas, implementadas nas décadas de 19902000 (muitas delas financiadas pelo Banco Mundial). A revisão desta literatura não cabe, contudo, nos limites deste artigo (neste sentido, consultar Gameiro, 2013). Ao longo deste trabalho (especialmente no tópico 5), mostraremos que o Banco Mundial aproximou-se e, quando conveniente, distanciou-se deste tipo de produção acadêmica, incorporando outras racionalidades científicas, conforme seus próprios interesses.

6. Nos documentos analisados, a instituição não apresenta uma definição conceitual do que entende por desenvolvimento rural.

7. Na nomenclatura utilizada pelo banco, países clientes (client countries) são aqueles tomadores de recursos, ou seja, os que efetivamente recebem empréstimos do banco.

8. Para uma importante então, a serem comuns num primeiro momento, valorizando o capital social e a abordagem territorial ${ }^{5}$.

Frente a tal contexto, o relatório Rural development: from vision to action propunha um quadro de planejamentos e estratégias da instituição com vistas à promoção do que o banco chamava de desenvolvimento rural ${ }^{6}$, para um horizonte de cinco anos. A preparação do documento teve início em dezembro de 1995, pela equipe de desenvolvimento rural do Banco, em colaboração com especialistas de outros setores da instituição - tais qual infraestrutura, saúde, planejamento familiar, nutrição, educação, desenvolvimento do setor privado e desenvolvimento social. Percebe-se aí a tentativa de mobilização de um recurso que Foucault (2009) chamou de princípio do "autor", um procedimento de organização interna dos discursos, segundo o qual a importância do indivíduo que fala ou escreve é diminuída frente ao seu princípio de agrupamento. A insígnia Banco Mundial como autor confere ao discurso unidade e coerência entre suas significações e, a depender do público com o qual interage, representa um indicador da verdade, participando do verdadeiro no conjunto de discursos de um campo do saber.

O Banco Mundial atrela seu envolvimento com o desenvolvimento rural ao maior objetivo declarado da instituição, que seria combater a pobreza nos países-clientes $^{7}$. Suas preocupações são claramente colocadas nas primeiras páginas do documento Rural development: from vision to action, e depois desenvolvidas em detalhes. A estimativa de que a demanda por alimentos possivelmente dobraria em 30 anos nos países em desenvolvimento colocava a necessidade, para o banco, de elevação da oferta de alimentos. Essa elevação deveria ocorrer por meio do crescimento da produtividade biológica das culturas e não da expansão de terras ou uso de irrigação, uma vez que terra e água seriam recursos finitos. Isso requereria o desenvolvimento de sistemas produtivos ambientalmente sustentáveis e altamente produtivos, tendo o setor privado um papel fundamental neste sentido (World Bank, 1997). Sem embargo, o argumento implícito aqui remete à noção de risco de Beck (2010), até mesmo por lembrar que a ampliação dos riscos relativizou as diferenças e fronteiras sociais, resultando num efeito equalizador que implodiria o esquema de classes. O Banco Mundial, ao referir-se à fome, à terra e à água, desperta ameaças relacionadas, por exemplo, à saúde e à legitimidade da propriedade privada. Tais ameaças não estariam confinadas a um tempo e a um lugar, e não se restringiriam a um "grupo de risco" 8 .

Ao buscar o fomento de um novo modelo, o banco apresenta no documento de 1997 os cinco princípios nos quais deveria assentar todas as ações da instituição voltadas ao desenvolvimento rural: 
i. o ambiente político e institucional (do país-cliente) deveria ser favorável ao sucesso do projeto;

ii. o setor privado deveria ser mobilizado, sempre que possível, para prover capital para investimentos, produção e serviços;

iii. o Estado deveria exercer novos papéis, distantes da intervenção rigorosa e atuando como facilitador dos ambientes macroeconômico, fiscal e político';

iv. uma pluralidade de instituições deveria estar envolvida, incluindo grupos da comunidade, municípios e altas instâncias de governo;

v. os projetos deveriam ser descentralizados e executados com alto grau de influência e participação das comunidades, associações e governos locais (World Bank, 1997).

Ao longo de todo o relatório From vision to action, a necessidade de construção de consensos em torno das ideias do banco é repetidamente destacada. Tais consensos minimizariam os conflitos existentes em torno das propostas de desenvolvimento rural e operariam como "comentários", um dos procedimentos de organização internos aos discursos (Foucault, 2009). Os comentários são textos que repetem, modificam e geram novos discursos sobre uma noção inicial (no caso, as propostas de desenvolvimento rural do banco), garantindo que os discursos primeiros do Banco Mundial sejam ditos e realizados.

Assim, a instituição afirma textualmente que grande esforço seria feito para promover maior consenso nos países-clientes, envolvendo o próprio presidente do banco em países-alvo cuidadosamente selecionados, e destaca ser esta a ação mais importante proposta no referido documento (World Bank, 1997). Os limitantes à ação do banco, por sua vez, são por ele reconhecidos:

O processo de formulação de estratégias e construção de consensos será constrangido pela disponibilidade do staff e dos recursos financeiros. Os esforços devem focar nos países onde o governo está suficientemente interessado. Onde falta interesse, ou onde a capacidade política para implementar as recomendações é fraca, o desenvolvimento de estratégias deve ser adiado até um momento mais oportuno (World Bank, 1997: 9, tradução dos autores).

Para responder à demanda que esperava criar, o banco avaliou a capacidade de seu staff. Na época, havia 470 especialistas trabalhando com desenvolvimento rural, incluindo mais de 100 consultores de longo prazo. Porém, em cinco anos, cerca de crítica sobre esta abordagem da supressão dos conflitos de classe, a partir da noção de risco, ver Acselrad, Mello \& Bezerra (2009).

9. A participação do Estado continua sendo importante no desenvolvimento rural, posto que os próprios projetos de financiamento do banco são firmados junto a governos estaduais ou federais, conforme a escala, e dependem largamente dos serviços públicos de extensão rural. No Brasil, exemplos de políticas com este desenho são os "programas de microbacias" dos estados de Santa Catarina, Paraná e São Paulo (Gameiro, 2013) 
um terço desses profissionais se aposentaria ou se afastaria (World Bank, 1997). Com o objetivo de recrutar e aprimorar a competência da equipe, o banco fez dos programas de treinamento um dos pilares estratégicos do From vision to action, de modo a garantir a apropriação social de seus discursos. A apropriação social dos discursos realiza-se, segundo Foucault (2009), por meio da educação - atributo político de manter ou modificar os discursos, com os saberes e poderes que eles trazem consigo. É possível aqui alargar o escopo da ideia de educação formal para uma noção mais ampla, relacionada, no caso dos programas de desenvolvimento rural do Banco Mundial, às atividades de treinamento e capacitação promovidas pelo próprio banco.

Neste sentido também contribui a contratação, por parte do Banco Mundial, de especialistas locais para compor as equipes de planejamento, execução e acompanhamento dos projetos da instituição. O documento em análise revela uma dupla intenção para esta estratégia. A mais difundida é que profissionais da localidade podem conhecer melhor as condições e demandas locais e apresentar mais habilidade para lidar com a heterogeneidade e complexidade de cada contexto específico. A menos mencionada, embora explícita no From vision to action, é que o uso de equipes localmente contratadas, particularmente na África e no sul da Ásia, tem por finalidade reduzir os custos dos projetos rurais do banco (World Bank, 1997). Em larga medida, a estratégia também tem potencial para contornar os limites à confiança nas relações de classe. Podemos inferir que os discursos técnicos são aceitos com mais facilidade quando há identificação entre o agricultor e o perito, ou seja, quando o agricultor identifica o técnico como pertencente ao "nós" (Gameiro, 2013).

A despeito desta "valorização" do capital humano local, o banco afirma que esforços devem ser realizados para levar conhecimento externo às áreas rurais, uma vez que o frequente isolamento físico das comunidades rurais pode dificultar a circulação de informações que colaborem para a elevação da produtividade agrícola e o bem-estar das famílias rurais. Este comentário traz implícita a imagem do rural atrasado, que depende da ajuda e dos conhecimentos dos novos fluxos informacionais para se desenvolver. Revela, desta feita, a influência da lógica dos espaços de fluxos (Castells, 1996) para exercer formas de dominação sobre os espaços de lugar, embora a capacidade de agência dos atores sociais e o prevalecimento de outras racionalidades nas comunidades rurais interfiram no grau de assimilação das "informações recebidas". Também levanta questões sobre a retórica existente por trás dos signos da descentralização e da participação da comunidade, pois o enaltecimento do conhecimento externo parece contraditório à valorização dos saberes locais implícita nestes mecanismos democráticos. Nestes termos, tal como se refere Martins (no 
prelo) a propósito dos processos de cientifização da política nas modernas arenas de governança socioambiental, trata-se da passagem da diferença à desigualdade sob a forma de capacitação dos agentes.

Ao ratificar a importância, para o banco, da difusão de seu know-how, e revelando preocupação com seus próprios interesses empresariais e comerciais, a instituição determina que países que representem riscos à instituição recebam apenas "assistência não financeira", assumindo a mobilização de seu saber perito como um recurso de poder (Giddens, 2002). A canalização de empréstimos para países com ambientes econômico e de governança favoráveis é bem enfatizada no documento, uma vez que o banco estabelece como meta atingir $80 \%$ de resultados classificados como satisfatórios na avaliação de seus projetos, num prazo de cinco anos (World Bank, 1997). Tal meta não deveria ser interpretada, porém, como um desestímulo aos acordos:

De fato, este programa de ações impulsiona fortemente projetos experimentais e inovadores. Mas propõe que esses projetos inovadores e arriscados sejam testados dentro de um programa aperfeiçoado de atividades não financeiras, de reformas políticas, desenvolvimento institucional e atividades-piloto, ao invés de serem parte de amplos programas de empréstimos. Projetos experimentais que mostrem boa probabilidade de sucesso em nível mais amplo poderão, depois, ser escalados para o financiamento (World Bank, 1997: 11, tradução dos autores).

Este interesse do Banco Mundial em prestar assistência técnica não financeira é um importante indicador da estratégia da instituição em atuar na definição do regramento legítimo do que pode ser considerado inovador no campo do desenvolvimento rural. Nos termos de Foucault (2009), é justamente esta modalidade de atuação que produz um dos exercícios fundamentais do poder, qual seja, o de interferir no regime de produção de verdade. A eficiência de tal interferência é ainda potencializada na medida em que, no caso em tela, o Banco Mundial agrega aos seus interesses o moderno discurso científico sobre economia e gerenciamento racional.

Este saber perito também tem o caráter de estrutura dual, moldando simultaneamente a ação e se constituindo fonte de informação e reflexão sobre o contexto em que a ação se dá, aprofundando seu caráter reflexivo. Em 2000, o Banco Mundial procedeu com avaliações ${ }^{10}$ sobre o desempenho das estratégias propostas três anos antes. Os resultados não foram satisfatórios, opinião que se materializou na publicação de um novo relatório propositivo de ações.
10. O relatório Rural development: from vision to action? (Phase II) foi publicado em junho de 2000 pelo Grupo de Avaliação Setorial e Temática, do Departamento de Avaliação de Operações do Banco Mundial. De circulação restrita, analisa o progresso e as percepções dos parceiros do Banco Mundial na implementação das propostas sugeridas no relatório From vision to action, de 1997 (fase 1), em cinco países: Letônia, Marrocos, Moçambique, Peru e Filipinas (World Bank, 2000). 
O relatório propositivo que seguiu ao From vision to action foi intitulado Reaching the rural poor - a renewed strategy for rural development, publicado em 2003. Também elaborado pela equipe de desenvolvimento rural do Banco Mundial, contou com extensiva contribuição das equipes regionais da instituição e de consultores externos, oriundos de empresas privadas, universidades, organismos multilaterais e governos, oferecendo consistência à estratégia de uniformização de discursos empreendida pelo banco. A preparação do documento foi apoiada financeiramente pelos governos da Holanda, França, Alemanha, Grécia e do Reino Unido.

Segundo o Banco Mundial (2003), as estratégias de desenvolvimento rural lançadas no relatório anterior, de 1997, "tiveram influência decisiva sobre o pensamento global, mas resultados práticos decepcionantes" (World Bank, 2003: XIV, tradução dos autores). Esta assertiva reitera o interesse maior do banco em fazer dos diagnósticos e das discussões produzidos por seu corpo perito efetivas prescrições próprias à intervenção sobre a realidade social. Ademais, indica as dificuldades de deslocamento do espaço de lugar à arena dos fluxos (Castells, 1996), um movimento fundamental para o banco avançar em estratégias inovadoras de desenvolvimento rural. Segundo a instituição, o insucesso das práticas decorreria majoritariamente das deficiências relacionadas aos países-clientes, diagnóstico que aloca em definitivo a responsabilidade aos lugares, eximindo a elaboração do projeto em si mesmo de falhas maiores.

A comparação entre os documentos indica apenas o reforço de estratégias cujas bases conceituais se fundamentam no relatório anterior, por vezes abordando de modo mais incisivo pontos que antes foram mencionados superficialmente - como o que se refere à economia rural não agrícola, ao qual dedica uma seção específica para designar as ações que deveriam fomentar esse segmento. O documento ressalta, porém, que, na maioria dos países, o conhecimento sobre o setor privado rural não agrícola era insuficiente para o efetivo desenvolvimento de intervenções, de modo que pesquisas e trabalhos setoriais seriam realizados para obter mais informações (World Bank, 2003). Novas visões acerca do rural estavam em curso, ressignificando a concepção das atividades produtivas, sobretudo agropecuárias, das relações sociais e do "rural" - categoria histórica - como patrimônio a ser usufruído e preservado (Wanderley, 2000).

Diante da avaliação de desempenho das ações anteriores, as propostas "renovadas" do Banco sugerem cinco aspectos principais:

i. maior enfoque à pobreza, incluindo questões de gênero, raciais e étnicas, que o banco classifica de "desenvolvimento rural holístico pró-pobre"; 
ii. promoção de um crescimento de base ampla, que reconhece a importância de economias rurais não agrícolas;

iii. enfoque do espaço rural em sua totalidade, numa abordagem intersetorial de longo prazo;

iv. fomento de alianças com todos os atores, impulsionando a participação e descentralização; e

v. atenção ao impacto de alterações no contexto global sobre os países-clientes (World Bank, 2003).

Esses cinco componentes, porém, não seriam trabalhados com a mesma intensidade em todos os países. O banco propõe planos de ação diferenciados por região geográfica ${ }^{11}$, os quais estabelecem as ações prioritárias e respectivas formas de abordagem. Esses planos regionais, segundo o banco, foram o resultado de intensivas consultas no âmbito de um amplo conjunto de atores, incluindo organizações locais, governos nacionais, empresas privadas, ONGs, acadêmicos e agências financiadoras (World Bank, 2003). Deste modo, confere-se validade às propostas, com a chancela de uma perícia que circula mesmo pelos espaços de lugares, agrupando sob a insígnia "Banco Mundial" muitos discursos que pavimentam o "verdadeiro" para legitimar a atuação financeira e política da instituição.

Ao delimitar as regras e as qualificações necessárias para discursar sobre o tema, bem como para fixar a eficácia suposta de suas palavras e o efeito sobre os quais elas se dirigem, o banco procede com a "rarefação dos sujeitos que falam" (Foucault, 2009). Isso fica evidente no documento Reaching the rural poor, quando a instituição destaca suas próprias "vantagens comparativas" para liderar um processo global de desenvolvimento rural. Além de se classificar como a maior provedora mundial de empréstimos para o desenvolvimento rural, com $60 \%$ de todo o montante de empréstimos agrícolas realizados por instituições financeiras internacionais, o banco delega a si mesmo um "poder de convocação". Com este poder, articula em torno de si uma rede de atores peritos e garante a eficácia no controle do discurso sobre desenvolvimento:

O Banco é a única instituição global capaz de reunir todos os atores e financiadores, incluindo o setor privado, para discutir assuntos importantes e traçar estratégias. Este "poder de convocação" possibilita ao banco desempenhar papel catalítico na definição de novas direções e agendas de desenvolvimento rural em termos globais, regionais e para países individualmente. [...] A diversidade de instrumentos disponíveis permite ao banco oferecer assistência

11. África, Ásia ocidental e Pacífico, Europa e Ásia Central, América Latina e Caribe, Oriente Médio e Norte da África, sul da Ásia. 
técnica politicamente orientada e dar suporte à implementação de políticas por ele endossadas através de programas de investimento (World Bank, 2003: 20, tradução dos autores).

12. A legitimidade conferida ao Banco Mundial como fonte de dados, produtor de análises comparativas e guia para políticas de desenvolvimento da passagem do século XX ao XXI pode ser observada pela circulação de seus documentos e relatórios. Um importante indicador é o fato de que, em meados da primeira década deste século, as publicações do Banco Mundial eram mais citadas que a média das revistas de economia (Pereira, 2010).

13. A edição de 2008 do World development report foi coordenada pelo australiano Derek Byerlee (então conselheiro de estratégias rurais do Banco Mundial) e pelo francês Alain de Janvry (professor de economia agrícola e políticas públicas na Universidade da California), sob orientação do economista francês François Bourguignon, então vicepresidente sênior e economista-chefe do Banco Mundial (em outubro de 2007, Bourguignon aposentou-se do Banco Mundial e tornou-se diretor da Paris School of Economics).
No propósito de adensar este capital de perícia ${ }^{12}$ em desenvolvimento rural, a instituição afirmava, no documento de 2003, ser uma instituição internacional de propriedade coletiva não dirigida por objetivos estreitos de maximização de lucros, o que lhe permitiria prover os seus clientes com suporte imparcial e plurianual para o desenvolvimento rural,

mesmo quando as condições políticas ou econômicas, ou os conflitos em dado país, não oferecem oportunidades de negócios imediatas e atrativas para instituições financeiras privadas (World Bank, 2003: 21, tradução dos autores).

Até este momento, portanto, os documentos do Banco Mundial aqui analisados revelam as tentativas da instituição de construção de gradientes de inteligibilidade sobre modelos de desenvolvimento rural que estavam em consonância com a expertise que vinha sendo produzida em campos variados do conhecimento, postulando que as funções do rural não se restringiam ao setor agrícola. Os empréstimos financeiros e a incorporação de agentes locais para a difusão das "vontades de verdade" do banco eram estratégias postas a serviço dos esforços de consolidação da influência dos fluxos sobre os lugares.

\section{O retorno à agricultura}

Em 2007, o Banco Mundial dedicou seu World Development Report 2008: agriculture for development (WDR) ao tema "agricultura para o desenvolvimento". O WDR é um relatório anual publicado pelo banco desde 1978, tendo se tornado uma das publicações de maior prestígio dentro da instituição. O relatório serve para sumarizar o "estado da arte" em várias áreas relacionadas a políticas de desenvolvimento e estabelecer um roteiro autorizado de discussão, ancorando-se e dando visibilidade à literatura afinada com os paradigmas da instituição. Sua confecção consumiria cerca de $10 \%$ do orçamento anual do banco para pesquisa (Pereira, 2010). O tema do WDR é escolhido pelo presidente da instituição três anos antes de sua publicação. A equipe que elabora o WDR é liderada por um membro sênior do banco, com o suporte de muitos especialistas e consultores internos e externos à instituição, sob orientação de seu economista-chefe ${ }^{13}$. A realização do documento foi apoiada financeiramente por vários fundos internacionais, como a Fundação Ford, o Ministério Francês de Assuntos Externos, Ministério das Finanças do Japão, e agências de desenvolvimento da Suíça, Suécia, Inglaterra e dos Estados Unidos. 
A justificativa para dedicar sua XXX edição ao tema "agricultura para o desenvolvimento" reside, segundo o banco, na constatação de que três em cada quatro pessoas pobres vivem em áreas rurais de países em desenvolvimento, e a maioria delas depende direta ou indiretamente da agricultura para sobreviver. O relatório pretendia, desta forma, orientar os governos e a comunidade internacional no desenho e na implementação de agendas que fizessem a diferença na vida de centenas de milhões de pobres rurais (World Bank, 2007).

O WDR 2008 serviu de base à publicação, em 2009, de outro documento, chamado Implementing agriculture for development: World Bank Group Agriculture Action Plan: FY2010-2012, que sumariza o programa pretendido pelo banco para o desenvolvimento rural nos três anos em questão. Ao ratificar sua intenção de construir discursos verdadeiros, afirma:

O Action Plan: FY2010-2012 pretende descrever como nós, do Banco Mundial, planejamos dar suporte ao grande consenso internacional representado pelo WDR 2008 (World Bank, 2009: VII, tradução dos autores).

Em comparação ao relatório de 2003, os documentos do Banco Mundial publicados em 2007 e 2009 conferem atenção relativamente maior à:

i. necessidade crítica de aumentar a produtividade agrícola, especialmente dos pequenos produtores pobres;

ii. diferenciação no mix de ajuda no âmbito dos "três mundos da agricultura" (países de base agrícola, países em transformação e países urbanizados), descritos no WDR 2008; e

iii. papel da agricultura em prover serviços ambientais, incluindo o contexto das mudanças climáticas (World Bank, 2009).

Observa-se, no geral, um reposicionamento do papel da agricultura para os espaços rurais, conferindo à atividade uma centralidade que havia sido, anteriormente, diluída nos discursos do banco.

As particularidades das agendas propostas pelo Banco Mundial para três distintos grupos de países são um elemento importante do WDR 2008. Grosso modo, aos países de base agrícola (da África Subsaariana, por exemplo) deveriam ser aplicados programas e políticas que "revolucionassem a produtividade" nas pequenas propriedades rurais. Nos países em transformação (sul e leste da Ásia, Oriente Médio e norte da África), o foco central deveria ser a diminuição da disparidade de renda, 
através de mudanças em direção à agricultura de alto valor (pecuária e horticultura, por exemplo) e às atividades econômicas não agrícolas no meio rural. Nos países urbanizados (como a maioria da América Latina e do Caribe, da Europa e da Ásia Central), a agricultura poderia ajudar a reduzir a pobreza rural se os pequenos produtores se tornassem fornecedores diretos de modernos mercados de alimentos, se bons empregos na agricultura e agroindústria fossem criados e se mercados para serviços ambientais fossem introduzidos (World Bank, 2009).

Percebe-se, assim, que mesmo se as funções diferenciadas fossem visadas para as atividades agrícolas e pecuárias, conforme os níveis de desenvolvimento da economia de um país, a agricultura retornava ao centro do debate em sua articulação com os mercados. Neste contexto, é importante lembrar que tal documento sucedia à crise dos preços dos alimentos que teve início em 2006-2007, com pico em 2008 , quando os preços internacionais registraram aumento de $83 \%$ em relação aos três anos anteriores, segundo o Banco Mundial. Questões como a volatilidade dos preços e seus efeitos sobre a segurança alimentar - tanto nos países desenvolvidos como nos países em desenvolvimento - associadas ao controverso avanço dos biocombustíveis e às oscilações nos preços do petróleo, renovaram o interesse do banco por temas como o aumento da produtividade agrícola e a inserção dos agricultores no mercado (Shaw, 2011).

Com efeito, a prescrição para o que o banco denominaria os "três mundos da agricultura" pode ser melhor compreendida se relacionada com o regime de verdade em torno da economia internacional que a própria instituição se esforçava em adensar. Conforme destacou Rosset (2004), em trabalho sobre a política fundiária do Banco Mundial, estudos comparativos entre países empreendidos pelos economistas da instituição davam conta, desde a década de 1990, de que a distribuição excessivamente desigual de "bens" - como a terra - retardava as taxas nacionais de crescimento econômico, com impactos severos sobre as decisões de alocação de capital dos investidores e a provável geração de tensões políticas. Nominalmente, esta seria uma das explicações para o baixo investimento em áreas rurais da América Latina, África e Ásia, não por acaso os alvos das novas proposições de desenvolvimento rural. Faz-se circular, sob as prescrições supra, enunciados sobre o que seria a verdade das trocas e dos interesses econômicos - enunciados estes com concretos efeitos de poder. 


\section{A agricultura e o clima}

Em 2013, o Banco Mundial publicou o relatório Implementing agriculture for development: World Bank Group Agriculture Action Plan: FY2013-2015, o qual, combinado com o Action Plan: FY2010-2012, abordado na seção anterior, resulta num período contínuo de seis anos de operacionalização do WDR 2008. A elaboração do Action Plan 2013-2015 (assim como a do 2010-2012) foi coordenada por Robert F. Townsend, economista-sênior do Programa Global de Agricultura e Segurança Alimentar do Banco Mundial, com a participação de membros do staff do banco locados em diferentes regiões e departamentos. Por se tratar de um relatório de estratégias operacionais, nota-se que a interferência de especialistas externos é limitada, descomprometendo o banco da necessidade de articular-se à expertise produzida fora de seus quadros e desconectando-o da produção acadêmica que, no início desta análise, legitimou a posição da instituição no campo discursivo do desenvolvimento rural. Observa-se ainda em tais planos de ação a presença mais consistente de profissionais vinculados à International Finance Corporation (IFC), segmento do Grupo Banco Mundial que apoia investimentos privados classificados como "sustentáveis e lucrativos", direcionados a países em desenvolvimento.

No Plano 2013-2015, a instituição promete dar continuidade ao crescente compromisso do Grupo Banco Mundial com a agricultura e os setores relacionados, injetando entre US\$ 8 e US\$ 10 bilhões ao ano até 2015, ante US\$ 6,2 bilhões ao ano, em média, no período 2010-2012 (World Bank, 2013). Seu foco predominante permaneceria sendo a elevação da produtividade e resiliência agrícola, especialmente para pequenos agricultores. A questão ambiental, no entanto, adquire maior importância nas prescrições do banco, legitimando os investimentos no setor agrícola. O documento ressalta a ênfase no que denomina de climate-smart agriculture (em tradução livre: agricultura esperta para o clima), bem como para o incentivo a respostas do setor privado, a administração de riscos de longo prazo, o gênero, a nutrição e as landscape approaches (ou abordagens via/pela paisagem) para a agropecuária e o uso da terra no geral.

Ao operar nos espaços de fluxos e dispondo de recursos sofisticados de perícia e fichas simbólicas, o banco executava, à época, um programa amplo, com atuação em 93 países e suporte a investimentos de longo prazo como pesquisa e extensão agrícola, gestão de águas em áreas irrigadas (novas ou já existentes, num total de 1,2 milhão de hectares), gestão de práticas agrícolas (apoio a 3 milhões de dias de treinamento para os clientes), e a adoção de novas tecnologias (por parte de 600 mil agricultores) (World Bank, 2013). Os resultados, pelo menos para a instituição, são válidos: 
Os retornos econômicos dos investimentos do banco em agricultura, que vêm melhorando ao longo do tempo, têm sido relativamente elevados, com lucro médio de 24\% (World Bank, 2013: xVI, tradução dos autores).

Entre os períodos fiscais 2006-2008 e 2010-2012, o banco aumentou seu suporte à agricultura e aos setores relacionados em $70 \%$. Os investimentos da International Finance Corporation (IFC) mais do que dobraram no período, com notável expansão para a África subsaariana, onde triplicaram. A influência dos fluxos sobre os lugares não é, portanto, apenas simbólica.

O gradativo deslocamento discursivo do Banco Mundial para a agricultura neste período, em detrimento ao incentivo às atividades rurais não agrícolas dos primeiros relatórios analisados, ganha respaldo ao ser articulado ao tema das mudanças climáticas. Já no World development report 2010: development and climate change, dedicado ao tema "Desenvolvimento e mudança climática", o banco enfatizava que a mudança do clima diminuiria a produtividade agrícola na maioria dos países e imporia pressões conflitantes para a agricultura, relacionadas à temperatura e ao regime de chuvas, à demanda por água, aos eventos climáticos extremos e às emissões de gases de efeito estufa. Segundo o banco, o desafio se torna maior quando se considera que a produção de alimentos, energia e fibras precisará dobrar até 2050 e, ao mesmo tempo, conservar os ecossistemas que armazenam carbono e oferecem outros serviços essenciais. A questão da terra é, então, abordada com a menção a estudos que indicam que a quantidade de terra globalmente disponível para a agricultura permanecerá a mesma até 2080 (World Bank, 2010) - um prognóstico preocupante, que pode servir de embasamento à corrida por terras.

É interessante observar que a mudança climática surge nos documentos do Banco Mundial não como tema envolto no que se convencionou denominar "questão ambiental". Ou seja, o apontamento da mudança climática não implica, neste caso, a recorrência ao debate mais amplo sobre justiça ambiental ou conservação dos recursos ecossistêmicos em favor das gerações futuras - tal como sugere a própria descrição das Organizações das Nações Unidas sobre o desenvolvimento sustentável (Brundtland, 1987) -, ou mesmo nos debates multilaterais empreendidos nos últimos anos envolvendo os governos nacionais. As transformações climáticas são registradas nos documentos do banco no que se relaciona estritamente à poluição econômica, compreendida como externalidade produzida pelo sistema econômico, com efeitos significativos sobre o próprio sistema:

As concentrações atmosféricas globais de $\mathrm{CO}_{2}$, o mais importante gás de efeito estufa, ficaram na faixa de 200 a 300 partes por milhão 
(ppm) durante 800 mil anos, mas saltaram para 387 ppm nos últimos 150 anos, principalmente por causa da queima de combustíveis fósseis e, em menor escala, da agricultura e alteração no uso da terra (World Bank, 2010: 4, tradução dos autores).

Como consequência desta abordagem - e isso certamente influencia toda a gramática desenvolvida pelos especialistas da instituição ao tratar o tema -, somente na medida em que a poluição física se manifesta como ameaça ao bem-estar econômico dos agentes privados é que ela se transforma efetivamente em custo social (Martins, 2013). Em outro trecho do relatório:

Um quarto da população mundial ainda vive com menos de US\$ 1,25/dia. Um bilhão de pessoas não tem água potável limpa; 1,6 biIhão não tem eletricidade e 3 bilhões, sanitarização adequada. [...] Ainda assim, a mudança climática deve ser urgentemente abordada. Mudanças no clima afetam todos os países, sendo aqueles em desenvolvimento os mais vulneráveis. As estimativas mostram que eles carregam entre 75 e $80 \%$ dos custos dos danos causados pela mudança climática. Mesmo um aumento de $2^{\circ} \mathrm{C}$. sobre as temperaturas pré-industriais - o mínimo que provavelmente experimentaremos - poderia resultar em reduções permanentes entre 4 e $5 \%$ no PIB da África e do sul da Ásia (World Bank, 2010: 22, tradução dos autores).

O banco constata que a maioria dos países em desenvolvimento não tem capacidade financeira e técnica suficientes para lidar com os riscos climáticos crescentes, e que tal queda no PIB decorreria de perdas na agricultura (World Bank, 2010). Deste modo, as recomendações feitas pela instituição financeira no World development report 2010 reforçam as estratégias postuladas no Agriculture action plan: FY 2013-2015: fortalecer a agricultura de pequena escala e construir uma resiliência climática, por meio de processos dirigidos pelo mercado, com a ajuda de investimentos privados (parcerias entre empresas e o IFC), maior acesso a insumos e sementes melhoradas, integração das economias locais a grandes mercados globais (World Bank, 2013). Nesse contexto, os agentes em posição de liderar os rumos do processo de mitigação das mudanças climáticas e de fortalecimento da agricultura "esperta para o clima" - ou, em outras palavras, de capitalizar sobre os recursos ecossistêmicos - estão estabelecidos. Na visão do banco:

A maior parte do crescimento das emissões ocorrerá nas nações em desenvolvimento, cuja pegada de carbono é desproporcionalmente baixa e cujas economias devem crescer rapidamente para reduzir a pobreza. Países de alta renda devem oferecer assistência financeira e técnica tanto para a adaptação como para o crescimento de baixo carbono nos países em desenvolvimento (World Bank, 2010: 23, tradução dos autores). 
O redirecionamento discursivo do banco em relação às suas prescrições para a agricultura e a ancoragem na poluição econômica encontra pistas também na leitura do relatório Localizing development: does participation work?, cujos autores principais são economistas do Grupo de Redução da Pobreza e Equidade e do Grupo de Pesquisa em Desenvolvimento, ambos do Banco Mundial. O documento, publicado em 2013, afirma que, na última década, o banco alocou quase US\$ 85 bilhões em projetos de desenvolvimento participativo local, baseado na crença que envolver as comunidades no desenho e na implementação de projetos cria uma conexão mais próxima entre a "ajuda ao desenvolvimento" e os "beneficiários pretendidos", leva a um grau mais elevado de cooperação e torna os governos mais responsáveis.

Porém, ao revisar mais de 500 estudos empíricos sobre intervenções para o desenvolvimento participativo, o documento chega, em linhas gerais, aos seguintes resultados: os participantes tendem a ser homens, relativamente mais ricos, mais estudados, ou dispõem de status sociais mais elevado (por casta ou etnia); são politicamente mais conectados que os não participantes e geograficamente menos isolados; a alocação de recursos tipicamente reflete as preferências dos grupos locais mais fortes; os projetos falham na construção de organizações coesas e resilientes, já que as redes formadas com os mecanismos participativos tendem a se dissolver quando os incentivos econômicos terminam. Ademais, tais políticas tendem a atrair grupos que já se encontram em melhor situação, tornando mais provável a exclusão de grupos realmente necessitados. O banco menciona evidências, também, de que a transferência de responsabilidades requer a criação de capacidades administrativas locais e que, na ausência dessas, os investimentos em infraestrutura são desperdiçados e os recursos naturais acabam mal manejados (World Bank, 2013b).

Contudo, quais conteúdos comporiam esta capacidade administrativa local? Parece certo que estes conteúdos se relacionam com a fluência sobre um conjunto de procedimentos de saber e de técnicas de intervenção sobre a vida dos corpos e das populações do campo. Assim, no que concerne ao meio ambiente, são capazes aqueles corpos e mentes docilizados para a sensibilidade ante a poluição econômica. No tocante ao desenvolvimento, a capacidade dos agentes torna-se aferível em suas respectivas disposições para a disciplina da figura abstrata do homo œeconomicus, voltado ao restrito cálculo das equações de investimento e lucro. Não parece ser por outra razão que, nas conclusões do banco, a dissolução dos incentivos econômicos nos programas de desenvolvimento rural é um dos pontos de partida para desarranjos de cooperação e exclusão de grupos sociais das arenas de participação.

Nesta descrição diagnóstica do banco sobre fragilidades dos processos participativos, também está implícita a composição de elementos de uma modalidade de 
tecnologia política dos corpos, nos termos de Foucault (1975), com um conjunto de saberes prontos para qualificar a verdade sobre as desigualdades na participação política de diferentes sujeitos no mundo rural e, por conseguinte, as prescrições necessárias para a superação do cenário de má participação. Esta tecnologia política, contudo, é nova justamente por escapar às fronteiras do Estado nacional - delimitação que levaria o filósofo francês a trabalhar com a noção de governança em termos de instituições estatais (Foucault, 2012). Mas a influência de novas arenas internacionais ou transnacionais nos debates sobre economia e desenvolvimento desloca algumas das batalhas discursivas também relativas à disciplina dos corpos para o espaço de fluxos. No caso do desenvolvimento rural, o repertório classificado como legítimo para a participação qualificada dos agentes no debate local articula conhecimentos técnicos que se estruturam em oposição à história local. Deste modo, as disputas dos grupos e das classes sociais locais, bem como a historicidade de seus conhecimentos da dinâmica ambiental do território - conhecimento também articulado às referidas disputas políticas - tornam-se alvos do controle dos fluxos sobre o lugar.

\section{Considerações finais}

O objetivo deste artigo foi discutir como os principais relatórios sobre desenvolvimento rural do Banco Mundial, publicados entre os anos de 1995 e 2015, promoveram novas categorias de descrição e prescrição do desenvolvimento rural para os chamados países em desenvolvimento. Com base na análise substantiva de cinco relatórios, o artigo pontuou os principais pilares do regime de verdade sustentado pela instituição sobre o mundo rural - regime que recorre, de maneiras variadas, aos recursos de cálculo e previsibilidade próprias da ciência moderna. Conforme também se buscou sustentar, a eficácia do discurso do banco articula-se com a fluidez dos novos espaços de dominação e exercício do poder em escala global.

A instituição articula e lidera redes de especialistas que circulam no espaço de fluxos - ver os arranjos entre o Banco Mundial, os Estados nacionais, as organizações como a FAO, as universidades, as empresas etc. Essas redes estabelecem, não sem conflitos, pretensos consensos (ou vontades de verdade) acerca do que é ou como deve ser o desenvolvimento rural, qual o papel da agricultura e que grau de prioridade deve-se relegar às preocupações ambientais.

Certamente, todos estes processos são capazes de afetar, em maior ou menor grau, as dinâmicas dos lugares em extensões deslocadas de tempo-espaço. Nesses consensos, outros grupos, majoritários em número, podem ver seus próprios 
interesses parcialmente representados dentro de uma estrutura de interesses dominantes, o que reveste de legitimidade as propostas do banco, por sua vez construídas de modo a contemplar os interesses políticos e econômicos próprios da instituição.

Com efeito, a legitimidade do poder da instituição (entendido como potencial de exercício de sua autoridade) não se baseia apenas em sua função econômico-financeira, ou nas fichas simbólicas representadas por seu potencial de realizar investimentos. Somado a isso - e para além disso - os laços de dominação do banco também estão relacionados com as verdades e prescrições que a instituição produz e transfere, seguindo técnicas de controle e sujeição do discurso.

\section{The rural development under regime of truth: the World Bank's discourses}

Abstract: This article aims to a sociological interpretation of the discourses of the World Bank in the field of cognitive struggles for the construction of knowledge and the legitimate prescriptions for rural development. These discourses were searched in five World Bank's reports dedicated to the theme from 1995 to 2015, which show a shift in agriculture's role to rural spaces. In the analyzed period, the initial documents the initial documents aim to build a broad view of rural, in a territorial approach that stimulates economic diversification and collective participation. Secondly, the emphasis shifts towards strengthening agriculture and the need to raise agricultural productivity to ensure food security; this position is reinforced at a third moment, when the Bank associates agriculture with climate change. The study highlights that the World Bank's prescriptions on rural development are largely based on the universal resources of calculation and predictability of modern science. The effect is the evaluation and the modeling of material and symbolic exchanges taken as legitimate in rural territories - actions that incur on practices of local population and demand the docilization of bodies for new institutional and market controls in the relation with the environment. At last, the effectiveness of the reform of the World Bank's discourses on rural development in emerging countries is also articulated with the fluidity of the spaces of domination and power exercise in global scale.

Keywords: rural development; new ruralities; ruralities and social theory; World Bank.

\section{Referências}

ABRAMOVAY, R. O capital social dos territórios: repensando o desenvolvimento rural. Economia Aplicada, v. 4, n. 2, p. 379-397, Abr./Jun. 2000.

ACSELRAD, Henri; MELLO, Cecília Campello; BEZERRA, Gustavo das Neves. O que é justiça ambiental. Rio de Janeiro: Garamond, 2009.

BECK, Ulrich. Sociedade de risco: rumo a uma outra modernidade. São Paulo: Editora 34, 2010. 
BRUNDTLAND, Gro Harlem (Dir.). Our common future. Report of the World Commission on Environment and Development. Oxford: Oxford University Press, 1987.

CARNEIRO, M. J. "Rural” como categoria de pensamento. Ruris, v. 2, n.1, Mar. 2008.

CASTELLS, Manuel. A sociedade em rede. "A era da informação: economia, sociedade e cultura", v. 1. São Paulo: Paz e Terra, 1996.

CASTRO, L. C. de. O desenvolvimento guiado por um elemento estrangeiro: as relações entre o Banco Mundial e os países subdesenvolvidos. Dissertação (Mestrado) - Programa de Pós-Graduação em Ciência Política, Instituto de Filosofia e Ciências Humanas, Universidade Estadual de Campinas (Unicamp), Campinas, 2004.

FAVARETO, Arilson da Silva. Paradigmas do desenvolvimento rural em questão. v. 1. São Paulo: Fapesp; Iglu, 2007.

FOUCAULT, Michel. Microfísica do poder. 25. ed. São Paulo: Graal, 2012.

—. A ordem do discurso. 18. ed. São Paulo: Loyola, 2009.

_. Surveiller et punir: naissance de la prision. Paris: Gallimard, 1975.

GAMEIRO, Mariana Bombo Perozzi. Desenvolvimento, perícia e poder no rural paulista: o caso do Programa Estadual de Microbacias Hidrográficas. Dissertação (Mestrado) - Programa de Pós-Graduação em Sociologia, Centro de Educação e Ciências Humanas, Universidade Federal de São Carlos (UFSCar), São Carlos, 2013.

GIDDENS, Anthony. Modernidade e identidade. Rio de Janeiro: Jorge Zahar, 2002.

—. As consequências da modernidade. São Paulo: Editora Unesp, 1991.

GONZALES, Manuel Jose Forero et alii. O Brasil e o Banco Mundial: um diagnóstico das relações econômicas. Brasília: Ipea, 1990.

HONE, Angus. World Bank operations: sectoral programs and policies. Baltimore; London: Johns Hopkins University Press, 1972.

LOWE, Philip et alii. Participation in rural development. Luxembourg: European Foundation for the Improvement of Living and Working Conditions, 1999.

MARSDEN, Terry; MURDOCH, Jonathan. The shifting nature of rural governance and community participation. Journal of Rural Studies, v. 14, n. 1, p. 1-4, 1998.

MARTINS, Rodrigo Constante. Fronteiras entre desigualdade e diferença na governança das águas. Ambiente e sociedade, (no prelo). 
MARTINS, Rodrigo Constante. A construção social da economia política da água. Sociologia. n. 73, p. 111-130, Lisboa, 2013.

MORMONT, Marc. Le rural comme catégorie de lecture du social. In: JOLLIVET, Marcel; EINER, N. (Orgs.). L'Europe et ses campagnes. Paris: Press des Sciences Politiques, 1996.

PEREIRA, João Márcio Mendes. O Banco Mundial como ator político, intelectual e financeiro (1944-2008). Rio de Janeiro: Civilização Brasileira, 2010.

PLOEG, J. D. van Der et alii. Rural development: from practices and policies towards theory. Sociologia Ruralis, v. 40, n. 4, p. 391-407, Netherlands, 2000.

ROSSET, Peter. O bom, o mau e o feio: a política fundiária do Banco Mundial. In: MARTINS, Mônica Dias (Org.). O Banco Mundial e a terra: ofensiva e resistência na América Latina, p. 16-24. São Paulo: Viramundo, 2004.

SHAW, D. John. The world's largest humanitarian agency: the transformation of the UN World Food Programme and of Food Aid. London: Palgrave Macmillan, 2011.

SCHNEIDER, Sérgio. A abordagem territorial do desenvolvimento rural e suas articulações externas. Sociologias, n. 11, p. 88-125, Porto Alegre, 2004.

VEIGA, José Eli et alii. A face rural do desenvolvimento: natureza, território e agricultura. Porto Alegre: Editora UFRGS, 2000.

WANDERLEY, Maria de Nazareth Baudel. A emergência de uma nova ruralidade nas sociedades modernas avançadas: o "rural" como espaço singular e ator coletivo. Estudos, Sociedade e Agricultura, n. 15, p. 87-145, Rio de Janeiro, Out. 2000.

WORLD BANK. Documents and reports. Disponível em: <http://documents.worldbank.org/curated/en/topic>. Acesso em: 29 Abr. 2015.

- What we do. Disponível em: <http://www.worldbank.org/en/about/what-we-do>. Acesso em: 04 Out. 2014.

- Implementing agriculture for development: World Bank Group Agriculture Action Plan: FY2013-2015. Washington: The World Bank Group, 2013.

(MANSURI, G., RAO, V.). Localizing development: does participation work? Washington: The International Bank for Reconstruction and Development/The World Bank, 2013b.

- World development report 2010: development and climate change. Washington: The International Bank for Reconstruction and Development; The World Bank, 2010. 
- Implementing agriculture for development: World Bank Group Agriculture Action Plan: FY2010-2012. Washington: The International Bank for Reconstruction and Development; The World Bank, 2009.

- World Development Report 2008: agriculture for development. Washington: The International Bank for Reconstruction and Development; The World Bank, 2007.

- Reaching the rural poor: a renewed strategy for rural development. Washington: The International Bank for Reconstruction and Development; The World Bank, 2003.

- Rural development: from vision to action? (Phase II). Washington: The World Bank Group, 2000.

- Rural development: from vision to action - A sector strategy paper. Washington: The World Bank Group, 1997. 
